\title{
Photoinduced Electron Transfer Reactions of tris(4,4'-dimethoxy-2,2'-bipyridyl)ruthenium(II)cation with Quinones in Aqueous Medium
}

\author{
T. Sumitha Celin, G. Allen Gnana Raj* \\ Department of Chemistry \& Research Centre, Scott Christian College (Autonomous), Nagercoil (affiliated to \\ Manonmaniam Sundaranar University, Tirunelveli), Tamilnadu 629003, India
}

*Corresponding author: E-mail: allengraj@gmail.com; Tel.: 09487311237

DOI: $10.5185 /$ amlett.2020.111575

Photoinduced electron transfer reactions of $\left[\mathrm{Ru}(\mathrm{dMeObpy})_{3}\right]^{2+}$ complex with quinones have been studied in aqueous medium by luminescent quenching technique. The complex shows an absorption and emission maximum of $448 \mathrm{~nm}$ and $608 \mathrm{~nm}$ respectively in aqueous medium. It has an excited state lifetime of $232 \mathrm{~ns}$. The quenching rate constant $k_{q}$ is sensitive to the nature of the quencher and the electron transfer distance between the luminophore and the quencher, the reduction potential of the quinones. The nature of quenching is confirmed from ground state absorption studies. The oxidative nature of quenching is confirmed from the formation of $\mathrm{Ru}^{3+}$ ion and quinone anion radical. Structural effects also influence the rate of electron transfer reaction.

\section{Introduction}

The photochemistry of organic and inorganic metal complexes has been an active area of research for many years. Inorganic photochemistry is concerned with the influence of light on inorganic ions, molecules and their coordination complexes. The monographs of Balzani and Carassitti on the photochemistry of coordination compounds [1] are important milestones in the evolution of inorganic photochemistry in recent times. Photophysical studies deal with the characterization of the structure, bonding and dynamics of electronically excited states. Photochemical studies deal with the study of uni and bimolecular reactions of the excited states. Among these properties, the energy, molecular geometries, dipole moment, redox properties, magnetic moment can change, on passing to the excited state [2]. Transition metal complexes have been found capable of utilizing visible light to engage organic molecules in redox chemistry. Of these, ruthenium polypyridyl complexes have been thoroughly studied for the past 30 years, due to their remarkable stability and photophysical properties [3]. Extensive work have been done after the discovery of the luminescence of $\left[\mathrm{Ru}(\mathrm{bpy})_{3}\right]^{2+}$ (bpy- 2,2'-bipyridyl) in 1959 by Paris and Brandt [4]. These complexes have potential application in the development of electron and energy transfer reactions, luminescence and solar energy conversion [5-7]. These luminescent complexes have applications such as photocatalyst [8-10], sensors for biomolecular [11-13], phototherapeutic agents $[\mathbf{1 4}, \mathbf{1 5}]$. The polypyridyl complexes are excellent photosensitizers from the view point of luminescence and electrochemical properties that are extensively investigated for the applications in inorganic and material chemistry [16].
The unique photophysical and photochemical properties of the ruthenium polypyridyl complexes allow them to be used in medical and technological applications. These metallo-complexes have received much attention in chemistry, biochemistry and pharmacy as promising compounds for the creation of novel drugs [17]. The $\mathrm{Ru}(\mathrm{II})$ ion has its advantage that, specific ligands can be introduced in a controlled manner due to its octahedral structure. The properties can also be tuned in a predictable way [18]. The properties can be tailored to a greater extend by introducing electron-donating and electronwithdrawing groups in the 4,4' - positions of 2,2'bipyridine(bpy), 4,7 - positions of 1,10-phenanthroline [19]. The intermediate anion is stabilized by the electronegative nitrogen atom. This results in a more stable anion when compared to the intermediate anion if the nucleophile is at the third position. Hence the favouring positions for nucleophilic substitution are the $4,4^{\prime}$ position in $2,2^{\prime}$-bipyridine and 4,7 position in 1,10 phenanthroline.

Quinones are ubiquitous in nature and they act as good electron acceptors. Quinones possess favourable redox potentials and can be converted to stable reduction products in a stepwise manner. The quinones are well known for their cytotoxicity. Quinones have very high toxicological and pharmacological effects. They are used as anticancer drugs. Antiviral, antifungal properties are some of their important properties. Quinones have the capacity to accept electrons and are easy to protonate. Quinones have a tendency to form stable hydrogen bonds. The electron accepting properties are also due to their favourable redox potentials and also due to their ability to get converted into stable reduction products such as hydroquinones via semiquinones. In order to understand 


\section{Advanced Materials Letters www.vbripress.com/aml}

the ET properties of quinones, several photosensitizers have been designed and studied. The present study deals with the photoinduced electron transfer reactions of tris(4,4'-dimethoxy-2,2'-bipyridyl)ruthenium(II) cation with quinones in aqueous medium.

\section{Experimental}

\section{Materials}

$\left[\mathrm{Ru}(\mathrm{dMeObpy})_{3}\right]^{2+}$ complex was synthesized by the reaction of $\mathrm{RuCl}_{3} .3 \mathrm{H}_{2} \mathrm{O}(1 \mathrm{mM})$ and 4,4'-dimethoxy-2,2'bipyridine $(3 \mathrm{mM})$. The two reactants were dissolved in $20 \mathrm{~mL}$ of ethylene glycol and refluxed for 4 hours. The solution was then allowed to cool at room temperature and filtered to remove any insoluble impurities. A saturated solution of sodium tetrafluoroborate was then added dropwise into the filtrate until an orange precipitate is formed. The product was filtered, washed with cold water and diethyl ether and further dried in a vacuum desiccator. The product was further purified by recrystallization $[20,21]$. The absorption maximum $\left(\lambda_{\mathrm{abs}}{ }^{\max }\right)$ and emission maximum $\left(\lambda_{\mathrm{em}}{ }^{\max }\right)$ of the complex in $\mathrm{CH}_{3} \mathrm{CN}$ are $448 \mathrm{~nm}$ and $590 \mathrm{~nm}$ respectively. ${ }^{1} \mathrm{H}-\mathrm{NMR}$ (DMSO- $\mathrm{d}_{6}$ ) $8.69(2 \mathrm{H}, \mathrm{d}), 7.5(2 \mathrm{H}, \mathrm{d}) 7.6(2 \mathrm{H}, \mathrm{d})$ and $2.5\left(6 \mathrm{H}\left(\mathrm{CH}_{3}\right), \mathrm{s}\right) . \mathrm{IR}$ $(\mathrm{KBr}) \quad 3000, \quad 1606,1136,733 \mathrm{v} / \mathrm{cm}^{-1}$. HRMS of $\left[\mathrm{Ru}(\mathrm{dMeObpy})_{3}\right]\left(\mathrm{BF}_{4}\right)_{2} \cdot \mathrm{m} / \mathrm{z}$ found $653\left(\mathrm{M}^{+}-2 \mathrm{BF}_{4}^{-}\right), 688$ $\left(\mathrm{M}^{+}-\mathrm{BF}_{4}^{-}\right)$.

The quinones were procured from Sigma Aldrich and were used as such without further purification. The double distilled deionised water was used for the studies. The same sample solutions of same concentrations were used for both absorption and emission spectral studies. The absorption spectrum was recorded using SYSTRONICS Double Beam Spectrophotometer 2203 and the emission spectrum using JASCO/FP 8600 spectrofluorometer. All the sample solutions used for emission measurements were deaerated for $\sim 30$ min using dry $\mathrm{N}_{2}$ gas purging by keeping the solutions in cold water to ensure that there was no change in the volume of the solution. All measurements were carried out at room temperature. Care has been taken to minimize solvent evaporation.

Transient absorption measurements were made with laser flash photolysis technique using an applied photophysics SP-Quanta Ray GCR -2 (10) Nd - YAG laser as the excitation source [22]. The time dependence of the luminescence decay was observed using a CzernyTurner monochromator with a stepper motor control and a Hamamatsu R-928 photomultiplier tube. The production of the excited state on exposure to $355 \mathrm{~nm}$ was measured by monitoring (pulse Xenon lamp of 250W) the absorbance change.

Electrochemical measurements were carried out using cyclic voltammetric technique. The measurements were taken in acetonitrile using CH16005E electrochemical workstation at room temperature. Cyclic Voltammetry measurements were carried out for $10^{-3} \mathrm{M}$ sample solution in acetonitrile consisting of $0.1 \mathrm{M}$ tert - butyl ammonium perchlorate supporting electrolyte with a conventional three electrode system containing a platinum working electrode, a platinum wire counter and a non-aqueous $\mathrm{Ag} / \mathrm{AgCl}$ reference electrode. The solutions were deoxygenated by purging pure $\mathrm{N}_{2}$ gas for $30 \mathrm{~min}$ prior to use. Cyclic voltammogram was taken was taken in aqueous medium also. The separation between the cathodic and anodic currents was taken as the criteria for reversibility. The redox potentials of the ground state couples and the zero-zero energy, $\mathrm{E}_{0-0}$ give the excited state redox potential (eqn.1).

$$
\mathrm{E}\left(\mathrm{Ru}^{2+*} \beta^{\beta+}\right)=\mathrm{E}\left(\mathrm{Ru}^{2+} \beta^{+}\right)-\mathrm{E}_{0-0}
$$

Here $\mathrm{E}\left(\mathrm{D}^{+} / \mathrm{D}\right)$ and $\mathrm{E}\left(\mathrm{A} / \mathrm{A}^{-}\right)$are the ground state and $\mathrm{E}\left(\mathrm{D}^{+} / * \mathrm{D}\right)$ and $\mathrm{E}\left(* \mathrm{~A} / \mathrm{A}^{-}\right)$are the excited state oxidation and reduction potentials of $\left[\mathrm{Ru}(\mathrm{dMeObpy})_{3}\right]^{2+}$ respectively and $\mathrm{E}_{0-0}$ is the zero- zero excitation energy of the complex.

\section{Results and discussion}

Steady state absorption and emission properties of $\left[\mathrm{Ru}(\mathrm{dMeObpy})_{3}\right]^{2+}$<smiles>O=C1C=CC(=O)C=C1</smiles><smiles>CC1=CC(=O)C=CC1=O</smiles>
1,4-benzoquinone 2-methyl-1,4-benzoquinone<smiles>CC1=CC(=O)C=C(C)C1=O</smiles>

2,6-dimethyl-1,4-benzoquinone<smiles>O=C1C=CC(=O)C(Cl)=C1</smiles>

2-chloro-1,4-benzoquinone

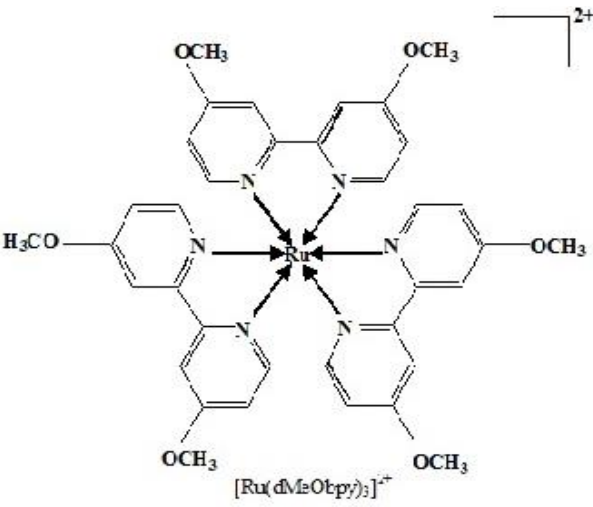

Fig. 1.Structure of quenchers and complex used.

The structure of quenchers used in the present study are shown in Fig. 1. The photochemical oxidations of $\left[\mathrm{Ru}(\mathrm{dMeObpy})_{3}\right]^{2+}$ complex with quinones in aqueous medium were studied using luminescence quenching technique. The luminescent measurements were performed at different quencher concentration and the metal complex concentration was kept constant. Samples 


\section{Advanced Materials Letters www.vbripress.com/aml}

solutions of the $\left[\mathrm{Ru}(\mathrm{dMeObpy})_{3}\right]^{2+}$ complex and the quinones were freshly prepared for each measurement. The $\left[\mathrm{Ru}(\mathrm{dMeObpy})_{3}\right]^{2+}$ concentration was fixed as $4 \times 10^{-5} \mathrm{M}$ and the quinone concentration was varied between $4 \times 10^{-6} \mathrm{M}$ and $2.8 \times 10^{-7} \mathrm{M}$. The absorption and emission spectra of the complex in aqueous medium are shown in Fig. 2. In aqueous medium the complex shows an absorption and emission maximum of $448 \mathrm{~nm}$ and $595 \mathrm{~nm}$ respectively. The absorption spectrum of $\left[\mathrm{Ru}(\mathrm{dMeObpy})_{3}\right]^{2+}$ with incremental concentration of $1,4-$ benzoquinone in aqueous medium is displayed in Fig. 3. This absorption spectrum shows the predominance of static quenching. In this type of quenching there will be a ground state complex formation occurs between the luminophore and the quencher and the absorption intensity slightly increases. Table 1 gives the ground state and excited state reduction potential of the metal complex in acetonitrile and aqueous medium. The excited state redox potentials are calculated from the ground state reduction potential using eqn. 1.
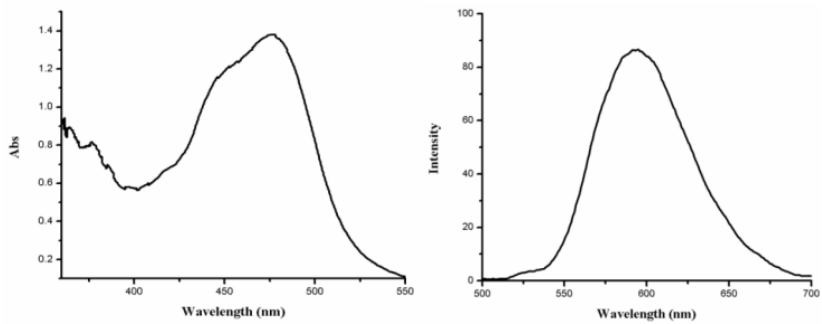

Fig. 2. Absorption and emission spectrum of $\left[\mathrm{Ru}(\mathrm{dMeObpy})_{3}\right]^{2+}$ complex in aqueous medium.

Table 1. Ground state and excited state redox potentials of $\left[\mathrm{Ru}(\mathrm{dMeObpy})_{3}\right]^{2+}$ in aqueous medium.

\begin{tabular}{llcc}
\hline Complex & $\begin{array}{c}\text { Ground state } \\
\text { redox } \\
\text { potential, }(\mathrm{V})\end{array}$ & $\begin{array}{c}\text { Excited state } \\
\text { redox } \\
\text { potential, }(\mathbf{V})\end{array}$ \\
\hline $\left.\mathrm{Ru}(\mathrm{dMeObpy})_{3}\right]^{2+}$ & aqueous & 1.1 & -1.0 \\
& Acetonitrile & 1.3 & -0.8 \\
\hline
\end{tabular}

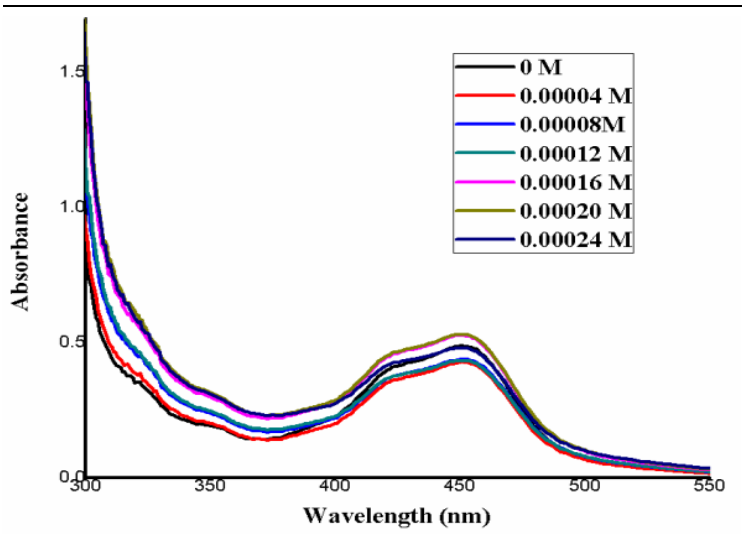

Fig. 3. Absorption spectrum of $\left[\mathrm{Ru}(\mathrm{dMeObpy})_{3}\right]^{2+}$ complex with incremental concentration of 1,4-benzoquinone in aqueous medium.

The emission maximum of $\mathrm{Ru}(\mathrm{II})$ complexes originate from the $\mathrm{d}_{\pi-\pi *} *^{3}$ MLCT transition. The coordinated $\left[\mathrm{Ru}(\mathrm{dMeObpy})_{3}\right]^{2+}$ has a $\mathrm{d}^{6}$ configuration with nearly octahedral geometry. The symmetry at the $\mathrm{Ru}$ site is $\mathrm{D}_{3}$. The polypyridine ligands are colourless molecules possessing $\sigma$ - donor orbitals, localized on the nitrogen atom and $\pi$ donor and $\pi^{*}$ acceptor orbitals more or less delocalized on the aromatic ring. Following a single configuration one electron description of the excited state in octahedral symmetry, promotion of an electron from a $\pi_{\mathrm{M}}$ metal orbital to the $\pi_{\mathrm{L}} *$ ligand orbitals give rise to a metal-to-ligand charge transfer (MLCT) excited states, whereas, promotion of an electron from $\pi_{\mathrm{M}}$ to $\sigma_{\mathrm{M}}{ }^{*}$ orbitals give rise to metal centered (MC) excited states.

The emission intensity of the complex $\left[\mathrm{Ru}(\mathrm{dMeObpy})_{3}\right]^{2+}$ are efficiently quenched in the presence of quinones in aqueous medium and are analysed in terms of the Stern - Volmer relationship. The change in luminescence intensity for the oxidative quenching of the $\left[\mathrm{Ru}(\mathrm{dMeObpy})_{3}\right]^{2+}$ complexes with various quinone concentrations in aqueous medium are analysed and are shown in Fig. 4.

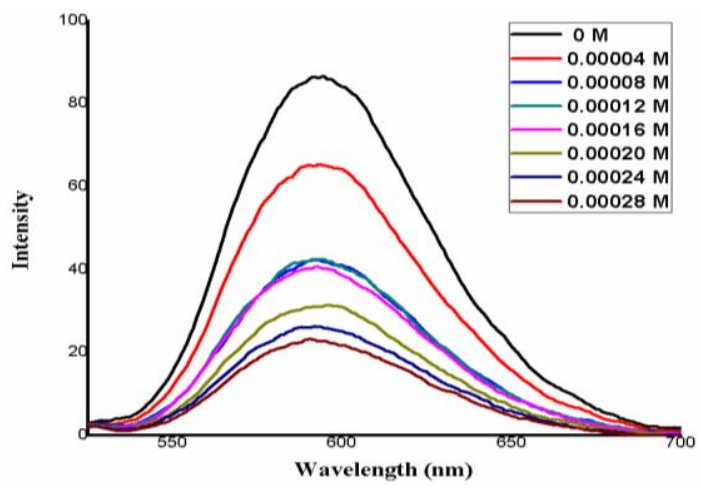

Fig. 4. Emission spectrum of $*\left[\mathrm{Ru}(\mathrm{dMeObpy})_{3}\right]^{2+}$ complex with incremental addition of 1,4-benzoquinone in aqueous medium.

\section{Stern volmer analysis}

Fig 5. shows the Stern -Volmer plot for the oxidative quenching of $*\left[\mathrm{Ru}\left((\mathrm{dMeObpy})_{3}\right)_{3}\right]^{2+}$ with $1,4-$ benzoquinone in aqueous medium. Stern-Volmer equation is used to calculate the quenching rate constant.

$$
\begin{aligned}
& \mathrm{I} / \mathrm{I}=1+K_{\mathrm{sv}}[\mathrm{Q}] \\
& K_{\mathrm{sv}}=k_{\mathrm{q}} \tau
\end{aligned}
$$

where $K_{\mathrm{sv}}, k_{\mathrm{q}}$, and $\tau$ are the Stern - Volmer constant, quenching rate constant and excited state lifetime respectively. The plot of $\mathrm{I}^{\mathrm{O}} / \mathrm{I} v s[\mathrm{Q}]$ is a straight line with an intercept of unity in all quenching studies.

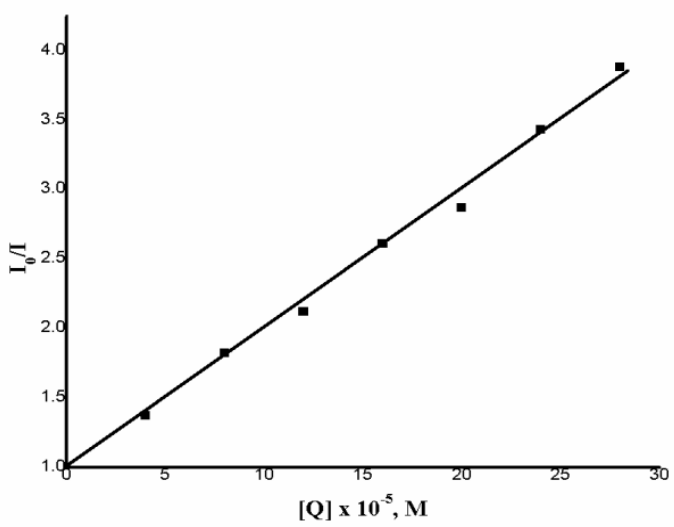

Fig. 5. Stern-Volmer plot for the oxidative quenching of $*\left[\mathrm{Ru}(\mathrm{dMeObpy})_{3}\right]^{2+}$ complex with 1,4 -benzoquinone in aqueous medium. 


\section{Advanced Materials Letters www.vbripress.com/aml}

Table 2. Association Constant $K_{\mathrm{a}}\left(\mathrm{M}^{-1}\right)$ and First order rate constant, $k_{\text {red }}\left(\mathrm{s}^{-1}\right)$ for quenchers with $\left[\mathrm{Ru}(\mathrm{dMeObpy})_{3}\right]^{2+}$ complexes in aqueous medium.

\begin{tabular}{lcc}
\hline Quinones & $\begin{array}{c}\text { Association } \\
\text { Constant } \boldsymbol{K}_{\mathbf{a}}\left(\mathbf{M}^{-\mathbf{1}}\right)\end{array}$ & $\begin{array}{c}\text { First order rate } \\
\text { constant, } \boldsymbol{k}_{\mathrm{red}}\left(\mathbf{s}^{\mathbf{- 1}}\right)\end{array}$ \\
\hline $\begin{array}{l}\text { 1,4-benzoquinone } \\
\text { 2-methyl-1, }\end{array}$ & $1.05 \times 10^{5}$ & $3.4 \times 10^{5}$ \\
$\begin{array}{l}\text { 4-benzoquinone } \\
\text { 2,6-dimethyl-1, } \\
\text { 4-benzoquinone }\end{array}$ & $1.43 \times 10^{5}$ & $7.8 \times 10^{4}$ \\
\hline
\end{tabular}

\section{Determination of association constant of quinones with} $*\left[\mathrm{Ru}\left((\mathrm{dMeObpy})_{3}\right]^{2+}\right.$ complexes

The association constant $\left(K_{\mathrm{a}}\right)$ for the formation of adducts between quinones and photoexcited $\mathrm{Ru}(\mathrm{II})$ - complexes, based on the integrated luminescence intensity emitted by the metal complexes in the presenceof different concentrations of the quencher are given in Table 2 . Association constant $K_{\mathrm{a}}\left(\mathrm{M}^{-1}\right)$ values obtained for quinones namely 1,4-benzoquinone, 2-methyl-1,4benzoquinone and 2,6-dimethyl-1,4-benzoquinone with $\left[\mathrm{Ru}(\mathrm{dMeObpy})_{3}\right]^{2+}$ complexes in aqueous medium are in the order of $10^{5} \mathrm{M}^{-1}$. From the earlier report [23], it is seen that the association constant in 50\% aqueous acetonitrile medium is of the order of $10^{4} \mathrm{M}^{-1}-10^{5} \mathrm{M}^{-1}$. The first order rate constant $\left(k_{\text {red }}\right)$ is calculated by taking the ratio of $k_{\mathrm{q}}$ and $K_{\mathrm{a}}$ in the excited state sensitizer quencher adducts. They are in the order of $10^{4}-10^{5} \mathrm{~s}^{-1}$ and is shown in Table 2. It is shown from the previously reported work [24] that the binding constant for the quenchers in presence of DMF is higher compared to the aqueous medium. The cause may be due to the high value of dielectric constant of water when compared to DMF. The dielectric constant of water is 80 whereas the value is 36 for DMF. Binding will also depend on the polarity. As DMF is an aprotic polar solvent, there is an enhanced association of the complex with the quencher than that of with polar protic solvent. It is seen that the quinones bind with the LC and MLCT absorption peak of the $\left[\mathrm{Ru}(\mathrm{dMeObpy})_{3}\right]^{2+}$ complex in the ground state. The ground state interaction between quinones and the bipyridine ring of the complex are hydrophobic or $\pi$ - $\pi$-stacking in nature. Benesi-Hildebrand plots for the luminescence quenching data of $\left[\mathrm{Ru}(\mathrm{dMeObpy})_{3}\right]^{2+}$ with incremental addition of 2,6dimethyl-1,4-benzoquinone in aqueous medium is shown in Fig. 6.

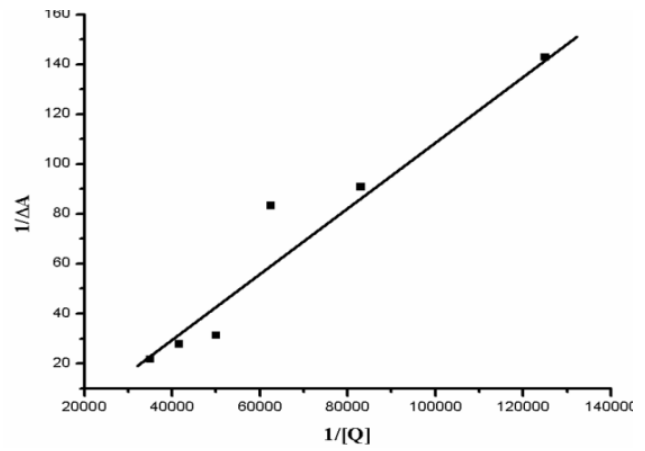

Fig. 6. Benesi-Hildebrand plot on MLCT absorption of $*\left[\mathrm{Ru}(\mathrm{dMeObpy})_{3}\right]^{2+}$ complex with incremental addition of $1,4-$ benzoquinone in aqueous medium.
The electron transfer distance between the donor and the acceptor also affects the rate constant $\left[\mathrm{Ru}(\mathrm{dmeObpy})_{3}\right]^{2+}$ has a radii of $7.9 \AA$ from $\mathrm{MM}_{2}$ molecular model calculation and the radius of quinones are in the range $2.7 \AA$ to $4.79 \AA$. The ET distance is the sum total radius of the donor and the acceptor. The ET distance of 1,4-benzoquinone, 2-methyl-1,4-benzoquinone and 2,6-dimethyl -1,4-benzoquinone are $10.6 \AA, 11.1 \AA$, $11.4 \AA$ respectively. 2,6-dimethyl -1,4 - benzoquinone has the highest ET distance. It has the least bimolecular quenching rate constant value.

\section{Luminescence quenching rate constant}

The bimolecular quenching rate constant $\left(k_{\mathrm{q}}\right)$ of $*\left[\mathrm{Ru}(\mathrm{dMeObpy})_{3}\right]^{2+}$ complexes with quinones, reduction potential of the quenchers $v s \mathrm{Ag} / \mathrm{Ag}^{+}$and Gibb's free energy change of the photoredox reaction $\left(\Delta \mathrm{G}^{0}\right)$ in aqueous medium are shown in Table 3. The $\Delta \mathrm{G}^{0}$ values are calculated from the excited state oxidation potential of $\left.\left[\mathrm{Ru}(\mathrm{dMeObpy})_{3}\right)_{3}\right]^{2+}$ complexes and reduction potential of the quinones.

Table 3. Luminescence quenching rate constant $\left(k_{\mathrm{q}}\right)$, reduction potential of quinones vs $\mathrm{Ag} / \mathrm{Ag}^{+}\left(\mathrm{E}_{\text {red }}^{0}\right)$ and free energy changes $\left(\Delta \mathrm{G}^{0}\right)$ for the oxidative quenching of $\left[\mathrm{Ru}(\mathrm{dMeObpy})_{3}\right]^{2+}$ complexes in aqueous medium.

\begin{tabular}{llcc}
\hline \multirow{2}{*}{ Quencher } & $\mathbf{E}^{0}$ red $v \mathbf{s}$ & \multicolumn{2}{c}{$\left[\mathbf{R u}(\mathbf{d M e O b p y})_{3}\right]^{2+}$} \\
\cline { 3 - 4 } $\mathbf{A g} / \mathbf{A g}^{+}(\mathbf{V})$ & $\boldsymbol{\Delta G}^{\mathbf{0}}(\mathbf{e V})$ & $\boldsymbol{k}_{\mathbf{q}}\left(\mathbf{M}^{-1} \mathbf{s}^{-1}\right)$ \\
\hline $\begin{array}{l}\text { 2- chloro -1, } \\
\text { 4- benzoquinone }\end{array}$ & 0.334 & -1.289 & $1.943 \times 10^{10}$ \\
1, 4 - benzoquinone & 0.242 & -1.207 & $3.658 \times 10^{10}$ \\
$\begin{array}{l}\text { 2 - methyl -1, } \\
\text { 4 - benzoquinone }\end{array}$ & 0.099 & -1.054 & $1.125 \times 10^{10}$ \\
$\begin{array}{l}\text { 2,6-dimethyl -1, } \\
\text { 4-benzoquinone }\end{array}$ & -0.088 & -0.867 & $6.288 \times 10^{9}$ \\
\hline
\end{tabular}

The luminescent quenching constant $k_{\mathrm{q}}$ is sensitive to the reduction potential of the quinones. Quinones with high reduction potential exhibit higher quenching rate constant and act as efficient quencher in the photo induced ET quenching. The compounds with one or more electron donating groups have lower reduction potential than 1,4benzoquinone.The value of quenching rate constant decreases as the number of electron donating groups in the quencher increases. Quinones with higher reduction potential exhibit higher quenching rate constant is indicative of ET quenching. The parent quencher 1,4- benzoquinone has the quenching rate constant of $3.658 \times 10^{10} \mathrm{M}^{-1} \mathrm{~s}^{-1}$ and the reduction potential is $0.242 \mathrm{eV} .2$ - methyl -1, 4-benzoquinone has the quenching rate constant of $1.125 \times 10^{10} \mathrm{M}^{-1} \mathrm{~s}^{-1}$. 2-chloro-1, 4-benzoquinone, has a higher bimolecular quenching constant than 2-methyl-1,4-benzoquinone.It is because of the electron withdrawing nature of the chloro group. These results indicate that the value of quenching rate constant depends on the presence of electron donating or electron withdrawing group on the parent quencher 1,4benzoquinone. Thus electron withdrawing groups have higher quenching rate constant than those with electron releasing groups. 
$\left.*\left[\mathbf{R u}^{\mathrm{II}}(\mathrm{dMeObpy})_{3}\right]^{2+}+\underset{\mathbf{k}_{21}}{\stackrel{\mathbf{k}_{12}}{\rightleftharpoons}} *\left[\mathrm{Ru}^{\mathrm{II}}(\mathrm{dMeObpy})_{3}\right]^{+} \underset{\mathbf{k}_{32}}{\stackrel{\mathbf{k}_{23}}{\rightleftharpoons}} *\left[\mathbf{R u}^{\mathrm{III}}(\mathrm{dMeObpy})_{3}\right]^{2+}-\mathrm{Q}^{-\cdot}\right]$<smiles>CC=CC(C)C</smiles>

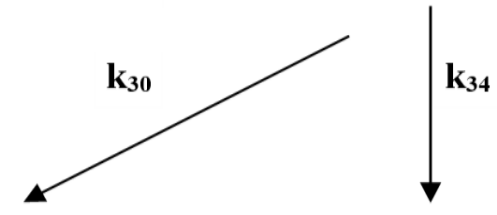

$\left[\mathbf{R u}^{\mathrm{II}}(\mathrm{dMeObpy})_{3}\right]^{2+}+\mathrm{Q}^{-} \longleftarrow\left[\mathrm{Ru}^{\mathrm{III}}(\mathrm{dMeObpy})_{3}\right]^{3+}$

${ }^{*}\left[\mathrm{Ru}^{\mathrm{III}}(\mathrm{dMeObpy})_{3}\right]^{2+}-\mathbf{Q}^{-}$

Scheme 1. Schematic mechanism for the ET quenching of $\left[\mathrm{Ru}(\mathrm{dMeObpy})_{3}\right]^{2+}$ with quinones.

The ET nature of the quenching of $*\left[\mathrm{Ru}(\mathrm{MeObpy})_{3}\right]^{2+}$ with quinones has already been established from laser flash photolysis study and the formation of quinone anion radical are reported for this [25-29]. The luminescence quenching of oxidative state ruthenium (II) complexes by quinones can be explained by Scheme 1 .

According to the scheme, the excited state donor $\left(\mathrm{Ru}^{\mathrm{II}}\right)$ and the ground state acceptor (quinone) molecules diffuse together to form an encounter complex, $\left({ }^{*} \mathrm{Ru}^{\mathrm{II}} \ldots \mathrm{Q}\right)$. This encounter complex then undergoes a reorganization to reach the transition state where ET takes place from the donor to the acceptor to give an ion-pair species, $\left(\mathrm{Ru}^{\mathrm{III}} \ldots \mathrm{Q}\right)$. For the successor complex, the parameters $K_{12}$ and $K_{21}$ are the diffusion controlled rate constants for the formation and dissociation of the encounter complex $\left(* \mathrm{Ru}^{\mathrm{II}} \ldots \mathrm{Q}\right), \quad$ respectively. The parameters $K_{23}$ and $K_{32}$ denote the forward and reverse rate constants. Apart from the formation of precursor complex $\left(K_{32}\right)$, the unpair state $\left(\mathrm{Ru}^{\mathrm{III}} \ldots . \mathrm{Q}\right)$, form the separated species $\mathrm{Ru}^{\mathrm{III}} \ldots \mathrm{Q}\left(K_{\text {sep }}\right)$ and undergo back ET to form the reactants in the ground state $\left(K_{34}\right)$.

The value of quenching rate constant also depends on the ET distance between the complex and the quencher. From $\mathrm{MM}_{2}$ molecular model, the calculated radius of 1,4benzoquinone, 2-methyl-1,4-benzoquinone, 2,6-dimethyl-

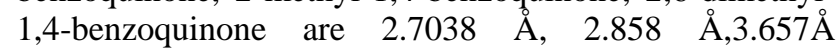
respectively. 1, 4-benzoquinone has the least radius. So the ET distance in 1,4-benzoquinone is minimum and thereby has the highest quenching constant when compared to 2-methyl-1,4-benzoquinone and 2,6dimethyl-1,4-benzoquinone.This is due to the low reduction potential value of $0.043 \mathrm{eV}$ for 1,4benzoquinone.

\section{Transient absorption spectral measurement}

The electron transfer nature of the reaction from the excited state $\mathrm{Ru}(\mathrm{II})$ complex to quinone, is confirmed from the transient absorption spectrum of the reaction mixture which was recorded using flash photolysis technique. Argon bubbled solution of $\left[\mathrm{Ru}(\mathrm{dMeObpy})_{3}\right]^{2+}$ complex was excited at $355 \mathrm{~nm}$ under laser flash photolysis. The spectrum at each time delay shows positive maxima centred at $440 \mathrm{~nm}$. Formation of substituted bipyridyl anion radical is confirmed from the absorption maxima at $530 \mathrm{~nm}$. In the presence of 2,6- dimethyl -1,4- benzoquinone, a new transient species is formed around $450 \mathrm{~nm}$ as shown in Fig. 7. This broad band was assigned to the quinone anion radical. The absorption at $450 \mathrm{~nm}$ is caused by the formation of quinone anion radical upon oxidative of $* \mathrm{Ru}(\mathrm{II})$ with quinone. Such positive signal is not got when we have the complex alone. Formation of $\mathrm{Ru}^{3+}$ ion and quinone anion radical confirms the oxidative quenching of $\left[\mathrm{Ru}(\mathrm{dMeObpy})_{3}\right]^{2+}$ complex with quinones in aqueous medium.

Based on these reports it is confirmed that quenching rate constants of photo induced ET reactions of $\left[\mathrm{Ru}(\mathrm{dMeObpy})_{3}\right]^{2+}$ with quinones in aqueous medium is slightly sensitive to the nature of substituents on the quencher, reduction potential, polarity of the solvent, Gibb's free energy change of the photoredox system, ET distance between the donor $\left[\mathrm{Ru}(\mathrm{dMeObpy})_{3}\right]^{2+}$ and the acceptor.

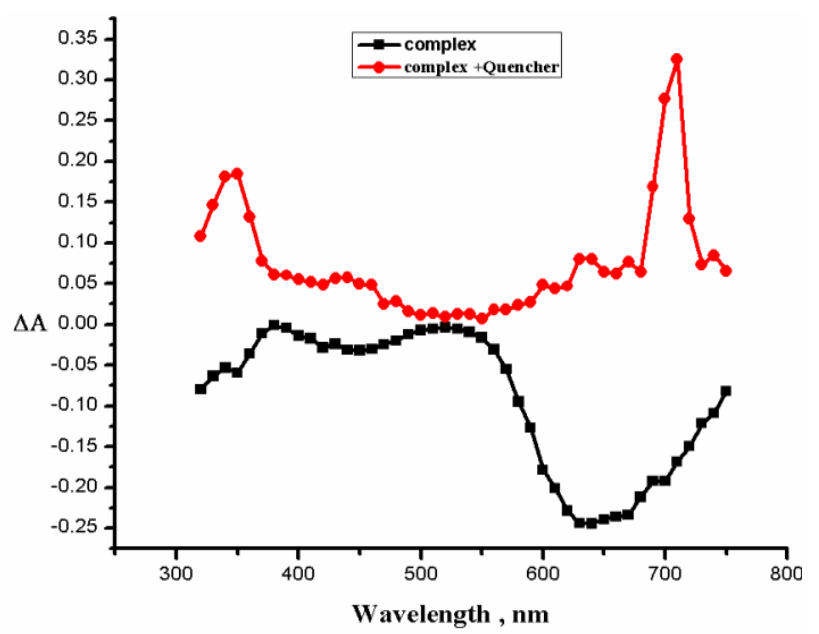

Fig. 7. Transient absorption spectra of $\left[\mathrm{Ru}(\mathrm{dMeObpy})_{3}\right]^{2+}$ complex in the absence and presence of 2,6- dimethyl-1,4-benzoquinone at $2.5 \mu$ s after $355 \mathrm{~nm}$ laser flash photolysis.

\section{Conclusion}

The photoinduced electron transfer reactions of $\left[\mathrm{Ru}(\mathrm{dMeObpy})_{3}\right]^{2+}$ complex with quinones in aqueous medium were studied by luminescence quenching technique. Absorption spectral data shows that the quenching is static in nature. The value of quenching rate 


\section{Advanced Materials Letters www.vbripress.com/aml}

constant is sensitive to the medium, structure of the quenchers used, the electron transfer distance between the luminophore and quencher. The study also confirms that other parameters like steric, structural, hydrophobic and $\pi$ $-\pi$ stacking interactions will have an effect on the electron transfer reactions of quinones with the excited state $*\left[\mathrm{Ru}(\mathrm{dMeObpy})_{3}\right]^{2+}$ complex. The detection of $\mathrm{Ru}^{3+}$ species and formation of quinone anion radical confirms the oxidation nature and electron transfer nature of quenching.

\section{Acknowledgements}

One of the authors T. Sumitha Celin, thank Dr. P. Ramamurthy, Director, National Centre For UltraFast Processes(NCUFP),University of Madras, Tharamani, Chennai for permitting to take lifetime measurements and transients.

\section{Conflict of interest statement}

The authors declare that there is no conflict of interest.

\section{Keywords}

Quinones, luminescence quenching, Stern-Volmer plot, photoinduced electron transfer.

Received: 31 March 2020

Revised: 03 June 2020

Accepted: 23 July 2020

\section{References}

1. Balzani, V.; Carassitti, V.; 'Photochemistry of Coordination Compounds', Academic Press, New York. 1970

2. Kalyanasundaram, K.; 'Photochemistry of Polypyridine and Porphyrin complexes', Academic Press Limited London, 1992 pp87-212.

3. Juris, A.; Balzani, F.; Campagna, S.; Belzer, P.; Von Zelewsky, A.; Coordination Chemical Review, 1988, 84,85.

4. Paris, J.P.; Brandt, W.W.; Journal of American Chemical Society, 1959, 81, 5001.

5. Gratzel, M.; Nature, 2001, 414, 338.

6. Gratzel, M.; Inorganic Chemistry, 2005, 44, 6841.

7. Giri Babu, L.; Singh, V.K.; Vijay Kumar, C.; Soujanya, Y.; Gopal Reddy, V.; Yella Reddy P.; Advances in Opto Electronics, 8.

8. Lela Duan, F.B.; Mandal, S.; Stewart, B.; Privalov, T.; Liobet, A.; Sun, L.; Nature Chemistry, 2012, 4, 418.

9. Chen, Z.; Chen, C.; Weinberg, D.R.; Kang, P.; Concepcion, J.P.; Harrison, D.P.; Brookhart, M.S.; Meyer, T.J.; Chemical Communications, 2011, 47, 12607.

10. Ohzu, S.; Ishizuko, T.; Hirai, Y.; Fukuzum, S.; Kojima, T.; Chemistry, An European Journal, 2013, 19, 1563.

11. Muthu Mareeswaran, P.; Babu, E.; Rajagopal, S.; Journal of Fluorescence, 2013, 23, 997.

12. Babu, E.; Muthu Mareeswaran, P.; Rajagopal, S.; Journal of Fluorescence, 2013, 23, 137.

13. Muthu Mareeswaran, P.; Maheshwara, D.; Balu, E.; Rajagopal, S.; Journal of Fluorescence, 2012, 22, 1345.

14. Taheri, S.; Behzad, M.; Nazari, H.; Khaleghian, A.; ISRN Inorganic Chemistry, 2013, 2013, 1.

15. Gill, M.R.; Thomas, J.R.; Chemical Society Reviews, 2012, 41 , 3179.

16. Shugai Wang; Songzhu Xing; Zhuolin Shi; Jiachen He; Quixia Han; Mingxue Li; RSC Advances, 2017, 7, 18024.

17. Biju Bennie, R.; Theodore David, S.; Joel, C.; Daniel Abraham, S.; Iyyam Pillai, S.; International Journal of Inorganic and Bioinorganic Chemistry, 2015, 5, 49.

18. Thangamuthu Rajendran; Gopalakrishnan Balakrishnan; Krishnan Senthil Murugan; Muthiah Chinnasamy; Kanimurugan Sivarajan; Ganesan Meiyalagan; Annadurai Madavan; Muniyandi Ganesan; Veluchamy Kamaraj Sivasubramanian; Journal of Physical Science, 2014, 25, 39.
19. Lasse Nurkkala.; 'Bipyridine capped oligothiophenes for directed energy and electron transfer in molecular electronic applications', Malardelan University Press Dissertation No.54. Malardelan University, Sweden, 2007.

20. Connors, K.A.; 'Binding Constants: The measurement of Stability', John Wiley \& Sons, Ltd. Chichester, U. K., 1987.

21. Swarnalatha, K.; Sornalatha, S.; Int. Journal of Advanced Research, 2016, 4, 235

22. Ramamurthy, P.; Chem. Educ.,1993, 9, 56.

23. Sumitha Celin, T; Allen Gnana Raj, G.; J. Adv. Chem. Sci., 2019, 5, 609.

24. Sumitha Celin, T; Allen Gnana Raj,G.; International Journal of Innovative Research in Science, Engineering and Technology, 2017, 6, 1478.

25. Kumbhakar, M.; Singh, P.K.; Nath, S.; Bhasikuttan, A.C.; Pal, H.; Journal of Physical Chemistry B., 2008, 112, 6646.

26. Satpati, A.K.; Kumbhakar, M.; Nath, S.; Pal, H.; Journal of Physical Chemistry B., 2007, 111, 7550.

27. Choudhury, S.D.; Kumbhakar, M.; Nath, S.; Sarkar, S.K.; Mukherjee, T.; Pal, H.; Journal of Physical Chemistry B., 2007, 111, 8842. Thanasekaran, P.; Wu, J.Y.; Manimaran, B.; Rajendran, T.; Chang, I.J.; Rajagopal, S.; Lee, G.H.; Peng, S.M.; Lu, K.L.; Journal of Physical Chemistry A., 2007, 111, 10953.

28. Thanasekaran, P.; Wu, JY.; Manimaran, B.; Rajendran, T.; Chang, IJ.; Rajagopal, S.; Lee, GH.; Peng, SM.; Lu, KL.; Journal of Physical Chemistry A., 2007, 111, 10953.

29. Thanasekaran, P.; Liao, RT.; Manimaran, B.; Liu, YH.; Chou, PT. Rajagopal, S.; Lu, KL.; Journal of Physical Chemistry A., 2006, 10, 10683.

\section{Authors biography}

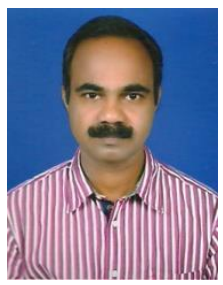

Dr. G. Allen Gnana Raj is an Associate Professor of Chemistry in Scott Christian College (Autonomous), Nagercoil, Tamilnadu, India since 1998. He is the Controller of Examinations from 2017. He got his Doctoral degree from Madurai Kamaraj University in 1994. His area of specialization is photochemistry. He is also expertise in Environmental Chemistry, Radiation Chemistry, Organic synthesis. To his credit he has guided $22 \mathrm{PhD}$ research scholars and 50 M.Phil scholars. He has published 98 articles in reputed journals.

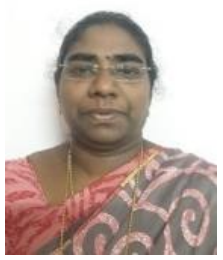

Dr. T. Sumitha Celin works as an Assistant Professor in the Department of Chemistry, Scott Christian College (Autonomous), Nagercoil, Tamilnadu, India since 2009. She got her post-graduation from The American College (Autonomous), Madurai. She cleared the SLET examination in 2004. She got her Doctoral Degree from Manonmaniam Sundaranar University in 2019.

\section{Graphical abstract}

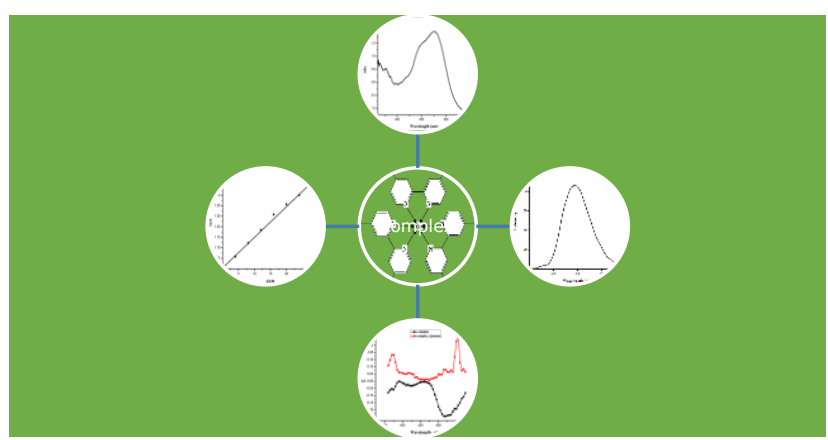

\section{Highlights}

- $\quad \mathrm{Ru}(\mathrm{II})$ polypyridyl complex undergo oxidative quenching with quinones.

- Transient absorption spectra confirm the formation of $\mathrm{Ru}^{3+}$ species and quinone anion radical. 